\title{
Influence of solar variability on the occurrence of central European weather types from 1763 to 2009
}

\author{
Mikhaël Schwander $^{1,2}$, Marco Rohrer ${ }^{1,2}$, Stefan Brönnimann ${ }^{1,2}$, and Abdul Malik ${ }^{1,2}$ \\ ${ }^{1}$ Institute of Geography, University of Bern, Bern, 3012, Switzerland \\ ${ }^{2}$ Oeschger Centre for Climate Change Research, University of Bern, Bern, 3012, Switzerland \\ Correspondence to: Mikhaël Schwander (mikhael.schwander@giub.unibe.ch)
}

Received: 18 January 2017 - Discussion started: 24 January 2017

Revised: 9 August 2017 - Accepted: 9 August 2017 - Published: 21 September 2017

\begin{abstract}
The impact of solar variability on weather and climate in central Europe is still not well understood. In this paper we use a new time series of daily weather types to analyse the influence of the 11-year solar cycle on the tropospheric weather of central Europe. We employ a novel, daily weather type classification over the period 1763-2009 and investigate the occurrence frequency of weather types under low, moderate, and high solar activity level. Results show a tendency towards fewer days with westerly and west-southwesterly flow over central Europe under low solar activity. In parallel, the occurrence of northerly and easterly types increases. For the 1958-2009 period, a more detailed view can be gained from reanalysis data. Mean sea level pressure composites under low solar activity also show a reduced zonal flow, with an increase of the mean blocking frequency between Iceland and Scandinavia. Weather types and reanalysis data show that the 11-year solar cycle influences the late winter atmospheric circulation over central Europe with colder (warmer) conditions under low (high) solar activity.
\end{abstract}

\section{Introduction}

The effects of solar activity changes on weather and climate in Europe are still not well understood. Although there is both empirical and model evidence of an imprint of the 11year sunspot cycle in the stratosphere, climate effects at the Earth's surface are less clear, nor are the mechanisms understood. Considering the rather small changes in the incoming energy over an 11-year sunspot cycle of ca. $0.1 \%$ (and perhaps also over longer periods), many of the suggested mechanisms are indirect and involve changes in atmospheric cir- culation (Gray et al., 2010; Seppälä et al., 2014, for a review). Therefore, analysing changes in atmospheric circulation with regard to the 11-year sunspot cycle might help to better attribute climatic changes to solar forcing. In this paper we analyse the imprint in atmospheric circulation over Europe.

Solar activity can have effects on the atmospheric circulation through three different mechanisms. These effects may arise from direct changes in total solar irradiance (TSI), from changes in stratospheric ozone and heating induced by changes in solar UV, or from changes in stratospheric ozone induced by energetic particles, whose flux is modulated by solar activity. The $\sim 1 \mathrm{Wm}^{-2}$ variation in TSI over an 11-year sunspot cycle corresponds to a change in the radiation forcing of about $\sim 0.17 \mathrm{Wm}^{-2}$ (Haigh, 2003; Gray et al., 2010). This change in radiation forcing is estimated to cause a change in Earth's surface temperature of approximately $0.07 \mathrm{~K}$ and - with a lagged response to changes in sea-surface temperatures (SSTs; Gray et al., 2010; Stevens and North, 1996; White et al., 1997). Circulation effects (bottom-up mechanism) may arise from unequal heating or ocean feedbacks that might involve the North Atlantic (Thiéblemont et al., 2015). The increased UV radiation during sunspot maxima leads directly to an ozone increase and associated heating in the upper stratosphere ( $\sim 40$ km, e.g. Matthes et al., 2004; Sitnov, 2009; Soukharev and Hood, 2006) and to changes in tropospheric circulation via downward propagation from the stratosphere (top-down mechanism). The suspected effects project strongly onto the North Atlantic European sector (Baldwin and Dunkerton, 2005). The energetic particle flux (proton and electron), which peaks in the declining phase of the sunspot cycle, 
leads to the production of $\mathrm{NO}_{x}$ in the mesosphere and stratosphere, which can destroy ozone in the stratosphere (Andersson et al., 2014; Päivärinta et al., 2013; Solomon et al., 1982). Through downward propagation, the troposphere can be affected, but a short phase lag is expected. Rozanov et al. (2012) showed that precipitating energetic particles can influence the chemical composition of the atmosphere as well as its dynamic down to the troposphere. The mechanisms might lead to different temporal (i.e. lagged or not) or spatial circulation changes; hence it is important to well characterize the circulation response of the 11-year solar cycle.

For all of the mechanisms, the response is expected to be pronounced over the North Atlantic European sector. In fact, many observation-based studies have found effects of the 11-year sunspot cycle in European weather and climate (e.g. Barriopedro et al., 2008; Brugnara et al., 2013; Huth et al., 2007; Ineson et al., 2011; Lockwood et al., 2010; Van Loon and Meehl, 2014). The impact of solar activity on variability modes such as the Atlantic Oscillation (AO) or the North Atlantic Oscillation (NAO) is often investigated. The $\mathrm{AO}$ - which is correlated with the NAO - was shown to be influenced in his intensity and variability by the 11-year solar cycle (Huth et al., 2007). The NAO was found to be linked to the 11-year cycle with a positive (negative) pattern being associated to high (low) solar activity (e.g. Gimeno et al., 2003; Ineson et al., 2011; Lockwood, 2012; Sfîca et al., 2015; Woollings et al., 2010). Ineson et al. (2011) investigated the NAO response to low solar activity in models with results displaying a pattern similar to the negative NAO phase. A similar pattern under low solar activity was shown in Woollings et al. (2010). Brugnara et al. (2013) did not find a significant correlation between the solar activity and the NAO, although they found a reduced westerly flow over the North Atlantic under low solar activity. Van Loon and Meehl (2014) showed that there is a positive phase of the NAO with strong negative sea level pressure anomalies in the North Atlantic during winter months when the NAO and the sunspot cycle maxima are in phase. When they are out of phase the NAO pattern is negative. Thiéblemont et al. (2015) found that the solar activity influence projects onto the NAO with the strongest signal visible with a 3-year lag. A similar lag is also presented in Gray et al. (2013). Scaife et al. (2013) proposed a mechanism to explain this lag through the direct response to solar UV irradiance change and the effect of the Atlantic SST on the NAO. The link between solar activity and the NAO is not supported by all studies. Van Oldenborgh et al. (2013) found no statistically significant linear relation between the sunspot number and the NAO.

The North Atlantic atmospheric circulation shows a response to the 11-year cycle, which leads to changes in the European weather. Atmospheric circulation over Europe is strongly correlated to the NAO and hence solar activity is thought to have an influence on weather conditions in Europe in winter. Studies show a preference of cold winters in Europe to be associated with minima in the 11-year solar cycle (e.g. Lockwood et al., 2010; Sirocko et al., 2012). Changes in the atmospheric circulation over the North Atlantic linked to solar activity might have an impact on European weather which could be visible on the persistence of specific weather patterns. For example Barriopedro et al. (2008) analysed the response of blocking duration in days to solar activity. They found that North Atlantic blocking persistence increases under low solar activity and the blocking is positioned more to the east.

Model simulations have also been used to investigate the solar activity impact on climate (see Gray et al., 2010, for a review). Uncertainties are, however, still large concerning the response in the troposphere. Models can reproduce the main influence of the solar activity on the troposphere but some of them have difficulties to reproduce details. For instance, Gray et al. (2013) found a lag in the solar response over Europe and the North Atlantic in observation data which was not confirmed by model simulations. Gray et al. (2013) also concluded that there is no consensus between climate models on the influence of the 11-year solar cycle and the linked mechanisms. Matthes et al. (2003) compared the response of several global circulation models to the 11-year solar signal over Europe and the North Atlantic. One of their conclusions was that the late winter dynamical response in the model is not comparable to observations. More recently the solar signal was analysed in CMIP-5 (Coupled Model Intercomparison Project Phase 5) simulations (Hood et al., 2015; Misios et al., 2016; Mitchell et al., 2015). For instance Mitchell et al. (2015) found a lag in the North Atlantic surface response to the 11-year solar cycle in the models - but weaker than in the observations. Not all models reproduce a similar response to the 11-year solar cycle in the stratosphere compared to observations, but some of them do reproduce an increase of the polar night jet under high solar activity (Hood et al., 2015).

Others studies looked at the impact of solar activity on climate at longer timescales. Martin-Puertas et al. (2012) used lake sediments to analyse variations in wind strength and the ${ }^{10} \mathrm{Be}$ accumulation rate for solar activity from 3300 to 2000 years before present. Their results show windy conditions in western Europe during late winter under a long period of low solar activity. Moffa-Sánchez et al. (2014) used foraminifer shells to reconstruct the SST and salinity of the North Atlantic over the past millennium. They found a correlation between centennial-scale variations in hydrography and total solar irradiance. On a shorter timescale, Sirocko et al. (2012) analysed the occurrence of cold winters in Europe back to 1780 using documentary data. Sirocko et al. (2012) found cold winters in Europe to be often linked to the lowactivity phase of the 11-year solar cycle. The time resolution of these studies covering a long period is coarse (centennial scale) or in the case of Sirocko et al. (2012) the method shows some weaknesses, as explained in van Oldenborgh et al. (2013). Van Oldenborgh et al. (2013) pointed out three problems in the data and methods of Sirocko et al. (2012). First, the selection of cold winters (freezing of the Rhine 
River) is subjective and incomplete. A second problem is the definition of low solar minima; they first select 4 years surrounding the minimum but in a second part only the single year following the minimum. The third issue is a disagreement in the relation between NAO and solar activity; van Oldenborgh et al. (2013) did not find any statistically significant linear relation between the winter NAO index and the sunspot number.

In this study, we analyse the influence of the 11-year solar cycle on daily central European weather types. The aim is to identify how the variations in the mean atmospheric circulation over Europe can be explained by changes in the occurrence of weather types. For this we apply a similar approach as Huth et al. (2008b) by looking at the occurrence of weather types over central Europe. There is a large panel of weather type classifications (WTCs) available for Europe based on various methods and covering different periods (Huth et al., 2008a; Philipp et al., 2010, 2014). Here we use a unique data set of daily weather types covering the period 17632009 (Schwander et al., 2017). It allows us for the first time to investigate the impact of the 11-year solar cycle on European climate with an analysis of weather statistics over almost 250 years. This analysis is performed by looking at changes in weather type occurrence as well as within-type changes.

This paper is structured as follows. The data and the methods used to analyse the solar activity influence on weather types, and reanalysis data are explained in Sect. 2. The results are presented in Sect. 3 and discussed in Sect. 4. We conclude this work in Sect. 5.

\section{Data and methods}

For our analysis of the impact of the 11-year solar cycle, we first computed the mean differences between low and high solar activity for the sea level pressure (slp), $500 \mathrm{hPa}$ geopotential height (z500), $850 \mathrm{hPa}$ temperature (t850), and blocking frequency for the period 1958-2009 for January to March (JFM). For this, we used the ERA-40 (from January 1958 to March 2002, Uppala et al., 2005) and ERA-Interim (from January 2003 to March 2009; Dee et al., 2011) reanalyses data set (same method as in Sect. 2.4) and the monthly sunspot number as a measure of solar activity (Sect. 2.1). ERA-40 and ERA-Interim were selected since they were originally used to compute the reference weather types (see Sect. 2.2) and were bilinearly remapped to $1^{\circ} \times 1^{\circ}$ to be combined. A two-tailed Student's $t$ test was used to determine the $95 \%$ probabilities that the low and high solar activity composites are from two different populations. Then we extended the analysis by using weather types (Sect. 2.2) with focus on the occurrence changes (Sect. 2.3) and within-type differences (Sect. 2.4). The method for deriving the blocking frequency used in the differences composites is described in Sect. 2.5.

\subsection{Solar activity}

The monthly sunspot number is used as a measure of the 11-year solar cycle (Fig. 1). It is the longest record of solar variability available; monthly sunspot data go back to 1700 . Sunspots correspond to zones of strong magnetic field; therefore, many visible sunspots are synonymous with an active Sun as the quiet Sun is free of any spot. The sunspot time series captures well the 11-year solar cycle and can therefore be used as a proxy for quantifying solar activity. The sunspot data were retrieved from the Sunspot Index and Long-term Solar Observations (SILSO) from the Royal Observatory of Belgium. We use the revised data series available since 1 July 2015.

\subsection{Weather type classification}

Weather types are used to determine whether the circulation differences observed in reanalyses are only due to changes in the mean circulation or whether they result from a change in the occurrence frequency of weather patterns. Weather types are a summary of recurrent flow patterns over a specific region, in our case central Europe and the Alpine region. For this, we use the CAP7 (cluster analysis of principal components) WTC (Schwander et al., 2017). CAP7 is a time series of daily weather types representing the mean atmospheric circulation in the Alpine region and central Europe during the period 1763-2009. This classification is a reconstruction of the CAP9 classification used by the Federal Office of Meteorology and Climatology MeteoSwiss (Weusthoff, 2011). CAP9 starts in 1957 and is updated to the present. The weather types were computed with the ERA40 and ERA-Interim reanalyses data set and directly from the Integrated Forecasting System (IFS) model after 2011. For CAP7, CAP9 was used as reference from 1958 to 1998 and was reconstructed back to 1763 using early instrumental data from European weather stations. The classification was reduced to seven types (hence CAP7) by combining similar, not well discriminated types (pairs of types having a similar mean slp pattern). Although CAP9 was originally computed for the Alpine region and contains a limited number of patterns, it - as well as CAP7 - captures the main circulation patterns over Europe and the North Atlantic. The seven types with their names and abbreviations are presented in Table 1. The weather types can be used to analyse changes in the frequency of occurrences (betweentype changes, Sect. 2.3) from 1763 to 2009 and to investigate changes in their composite (within-type changes, Sect. 2.4) with reanalysis data from 1958 to 2009 . The CAP7 classification ends in 2009 because some of the long instrumental data time series used for the reconstruction do not extend further in time (see Schwander et al., 2017). The mean frequency of occurrence of each type for JFM over the period 1763 to 2009 is shown in Fig. 2. The z500 (in geopotential decametres, gpdm) and slp (in hectopascals, hPa) com- 


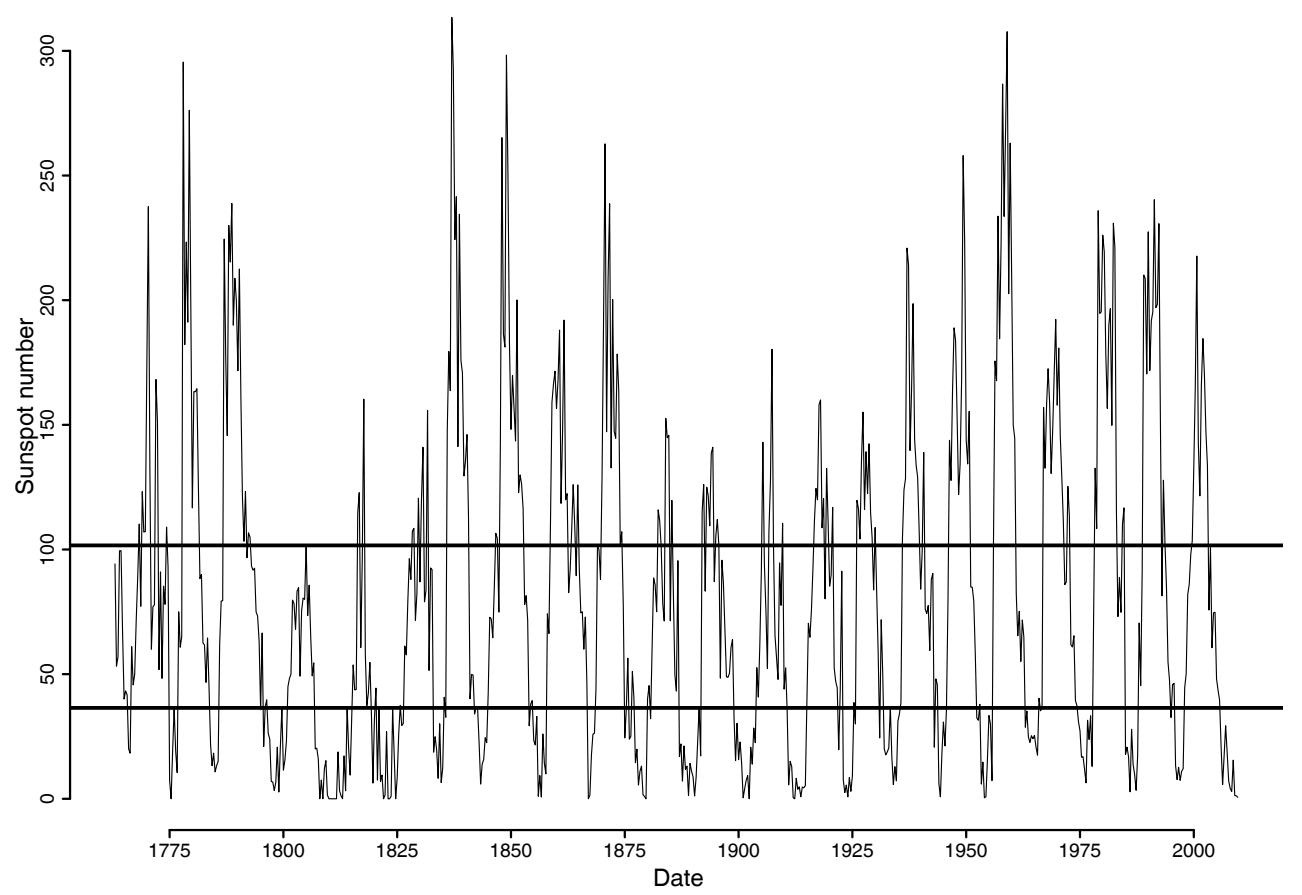

Figure 1. 1763-2009 JFM monthly sunspot number with 33rd and 66th percentile thresholds.

posites for 1958-2009 computed with ERA-40 (1958-2002) and ERA-Interim (2003-2009) for JFM are shown in Fig. 3. The classification contains three continental types (NE, E, and N), two westerly types (WSW and W), one cyclonic type (WC), and one anticyclonic type (HP). CAP7 is the only objective times series of daily weather types which covers almost 250 years in Europe. It also covers a longer period than any existing reanalysis (from which weather types can also be computed). For more information on the method of reconstruction, see Schwander et al. (2017). The daily weather types CAP7 are complemented with a probability value of each day being correctly classified (see Schwander et al., 2017). Since CAP7 is a reconstruction and cannot be compared to any other WTC back to 1763 , this probability value provides an indication on the reliability of the classification for each day. This allows us later to omit days with a probability lower than a certain threshold (e.g. $75 \%$ ).

\subsection{Weather type occurrences}

The following method is similar to the procedure applied in Huth et al. (2008b) but the CAP7 data set used here covers a longer period of time. A comparison with Huth et al. (2008b) can however be done over the second part of the 20th century. To capture the influence of the Sun on weather patterns, changes in the frequency of occurrence of the CAP7 weather types relative to variations in solar activity are analysed. It was shown that the strongest influence of solar activity on the lower troposphere is visible during the late winter months because of the delayed propagation of the signal from the
Table 1. CAP7 weather types numbers, abbreviations, and names.

\begin{tabular}{|c|c|c|}
\hline Index & Abbreviation & Full name \\
\hline 1. & $\mathrm{NE}$ & Northeast, indifferent \\
\hline 2. & WSW & $\begin{array}{l}\text { West-southwest, cyclonic, } \\
\text { flat pressure }\end{array}$ \\
\hline 3. & $\mathrm{~W}$ & $\begin{array}{l}\text { Westerly flow over northern } \\
\text { Europe }\end{array}$ \\
\hline 4. & $\mathrm{E}$ & East, indifferent \\
\hline 5. & $\mathrm{HP}$ & High pressure over Europe \\
\hline 6. & $\mathrm{~N}$ & North, cyclonic \\
\hline 7. & WC & $\begin{array}{l}\text { Westerly flow over southern } \\
\text { Europe, cyclonic }\end{array}$ \\
\hline
\end{tabular}

stratosphere to the troposphere (Ineson et al., 2011). Thus, the weather type analysis as well as reanalyses and model simulation analyses are performed on the months of JFM. The sunspot number data were first divided into three categories: low, moderate, and high solar activity using the 33rd and 66th percentile as thresholds (see Fig. 1). This method assumes that all solar minima reach a similar low intensity as the number of sunspot cannot go below zero. The daily weather types were then classified according to the corresponding solar activity level. For each weather type we computed the ratios of the frequency for each solar activity level (low, moderate, high) relative to the long-term mean. Results are calculated for the period January 1763 to March 2009 as well as for three sub-periods: 1763-1886, 1887-2009, and 1958-2009 (period of reanalysis data) for a comparison with 


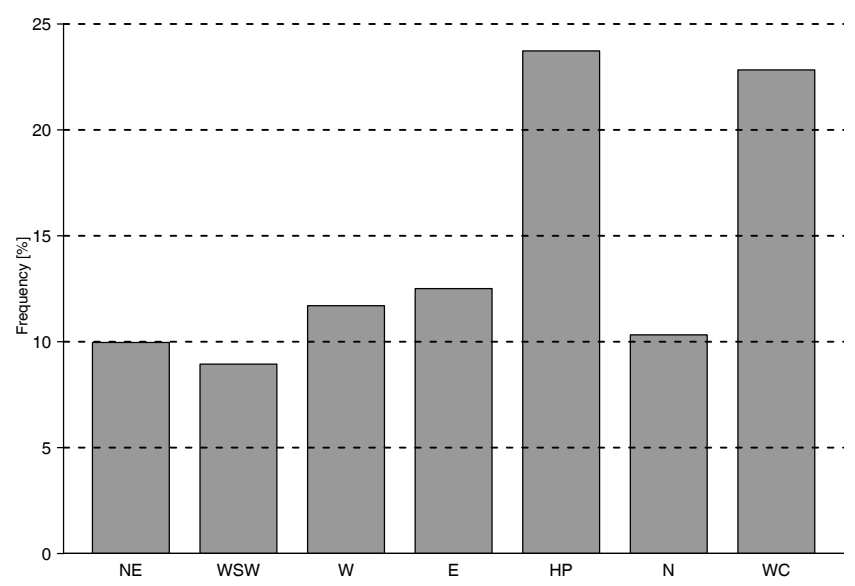

Figure 2. CAP7 1763-2009 JFM mean frequency of occurrence.

Table 2. Size (number of months) of each solar activity level and periods analysed.

\begin{tabular}{lrrrr}
\hline & $1763-1886$ & $1887-2009$ & $1958-2009$ & $1763-2009$ \\
\hline Low & 98 & 99 & 38 & 195 \\
Moderate & 108 & 102 & 35 & 211 \\
High & 106 & 105 & 47 & 212 \\
\hline
\end{tabular}

Huth et al. (2008b). We removed 3 years following large volcanic eruptions as they can have a significant influence on climate (see e.g. Robock, 2000). The three groups of solar activity are therefore of different sizes (see Table 2). The list of volcanic eruptions was taken from Arfeuille et al. (2014). A resampling method was used to test the significance of the ratios. The weather type series (for each period) was resampled 10000 times. The computed ratio is considered as significant when below (above) the 250th (9750th) value of the resample elements. Another histogram series (not shown) was computed using only days having a probability (to be correctly classified) superior to $75 \%$. We also computed the ratios with a 1-, 2-, and 3-year lag for the 1763-2009 period.

\subsection{Within-type differences}

In addition to the change in the weather types occurrences, we investigate the within-type difference of atmospheric fields between low and high solar activity levels for each of the seven weather types. For this, we computed composites for each weather type in order to identify changes in their mean circulation pattern over Europe and the North Atlantic under low and high solar activity. Composites of slp, z500, and t850 of each type were computed for the previously defined high and low solar activity classes for the period 1958-2009 (JFM). Additionally to these parameters, the mean blocking frequency was also computed for each composite (see Sect. 2.5). From these composites, differences were calculated by subtracting the high-activity from the low-activity composites. ERA-40 (January 1958-March 2002) and ERA-Interim (January 2003-March 2009) were used as the original CAP types were computed based on the ERA-40 and ERA-Interim mean slp field. The within-types analysis can therefore only be made over the period 19582009 and cannot be extrapolated back to 1763 .

\subsection{Blocking frequency}

A blocking is defined as a reversal of the meridional geopotential height $(\mathrm{GPH})$ gradient at $500 \mathrm{hPa}$. We follow the approach of Tibaldi and Molteni (1990) and extended the blocking algorithm to find blockings in a two-dimensional field following the procedure of Scherrer et al. (2006). The algorithm flags a certain longitude and latitude as blocked, if two criteria are fulfilled:

GPH gradient towards the pole

$\mathrm{GPHG}_{\mathrm{P}}=\frac{Z 500_{\varphi+14}-Z 500_{\varphi}}{14}<-10 \frac{\mathrm{gpm}}{{ }^{\circ} \text { lat }}$,

GPH gradient towards the Equator

$\mathrm{GPHG}_{\mathrm{E}}=\frac{Z 500_{\varphi}-Z 500_{\varphi-14}}{14}>0 \frac{\mathrm{gpm}}{{ }^{\circ} \text { lat }}$.

The latitude $\varphi$ varies from 36 to $76^{\circ}$ in $2^{\circ}$ intervals. ERA40 and ERA-Interim data were bilinearly interpolated to a $2^{\circ} \times 2^{\circ}$ before computation. Only blockings with a minimum lifetime of 5 days and spatial overlap larger than $70 \%$ between each time step are considered here.

\section{Results}

\subsection{Mean difference}

The differences computed between low and high solar activity with ERA-40 and ERA-Interim for 1958-2009 (Fig. 4) show a reduced zonal flow over Europe under low solar activity relative to high activity. The slp (in $\mathrm{hPa}$ ) is higher between Iceland and Scandinavia, and lower over southern Europe and the Mediterranean Sea. The z500 (in gpdm) differences have a similar pattern but with higher values which extend more to the west over Greenland. The blocking frequency (in percent, \%) is also higher over this region under low solar activity, especially over Iceland, the northern British Isles, and western Scandinavia, where it is significant at the $95 \%$ level. The higher values extend also to the southwestern part of Europe. The t850 (in degrees Celsius, ${ }^{\circ} \mathrm{C}$ ) is reduced over most of the European continent and North Africa, and higher over Greenland, the northern British Isles, and Scandinavia.

\subsection{Solar signal in the occurrence of the weather types}

The frequencies of occurrence of CAP7 weather types for different solar activity levels for JFM are shown in Fig. 5. 


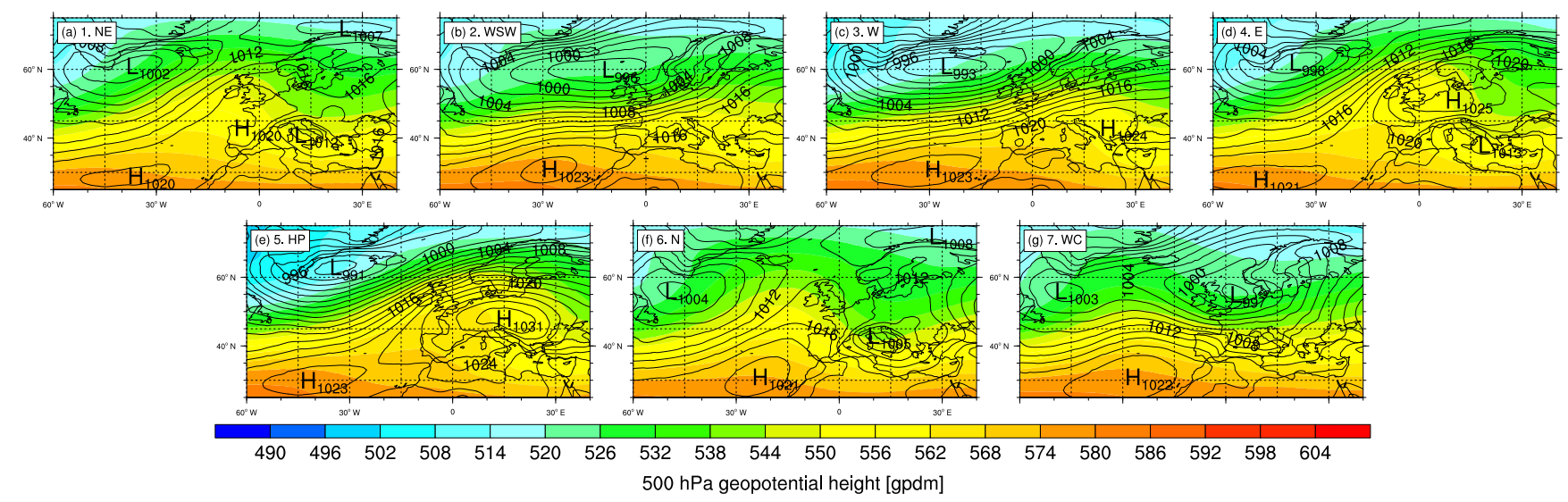

Figure 3. CAP7 1958-2009 $500 \mathrm{hPa}$ geopotential height (colour) in gpdm and sea level pressure (contours) in hPa JFM composites.
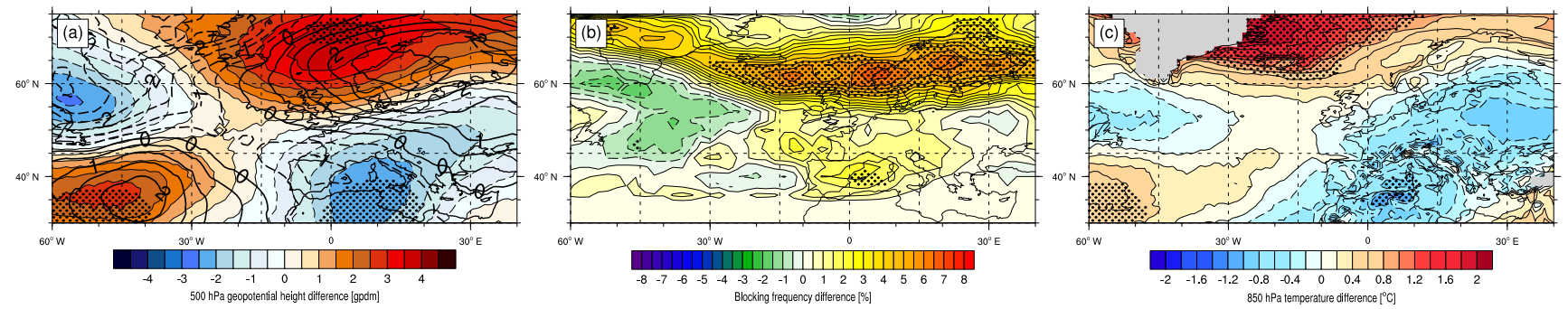

Figure 4. 1958-2009 low minus high solar activity differences computed with ERA-40/Interim. (a) 500 hPa geopotential height (colour) in gpdm and sea level pressure (contour) in $\mathrm{hPa}$. (b) Blocking frequency in \%. (c) $850 \mathrm{hPa}$ temperature in ${ }^{\circ} \mathrm{C}$. The $95 \%$ significance level is indicated with stippled areas.

The size of the groups (number of months) is displayed in Table 2. The histograms display the ratios computed between the low, moderate, and high solar activity frequencies and the long-term mean frequency. Histograms (a) and (b) correspond to a 123 and 122 year period (1763-1886 and 18872009). Histogram (c) (1958-2009) corresponds to the reanalysis period and roughly to the period (1950-2002) analysed in (Huth et al., 2008b). Histogram (d) shows the whole period (1763-2009). For these last 50 years (Fig. 5c), the northerly $(\mathrm{N})$, northeasterly (NE) and easterly (E) types have the highest ratios under low solar activity but only the northerly type ratio is significantly different from 1 . At the same time, the west-southwesterly (WSW) and high-pressure (HP) types have the lowest ratios (significant for HP). Under high solar activity, the easterly (E) and northerly (N) types have a ratio lower than 1 (significant for E). Under medium activity, no ratio is significantly different from 1 .

For the other sub-periods of time (a) and (b) the ratios do not all show a similar signal. For example, the $\mathrm{N}$ type ratio is slightly lower than 1 for the sub-period (a) but higher than 1 for sub-period (b) under low solar activity. This kind of variability is visible in most of the weather types. Another example is the HP type with a ratio significantly higher (lower) than 1 under low (moderate) solar activity in sub-period (a) but no signal in sub-period (b). Some weather types have similar ratios in both (a) and (b). For example, under low solar activity the W and WSW type ratios are lower than 1 .

Although it can be difficult to deduce a general structure (similar ratios under the same solar activity level) in the weather types occurrences between the different sub-periods (a), (b), and (c), there are some significant changes in the mean occurrence frequencies of some of the types over the whole time series (1763-2009, (d)). Under low solar activity, we observe significantly lower ratios of WSW and W types, and significant higher ratios of E type. Under moderate and high solar activity the higher $\mathrm{W}$ type ratios are significant. Under moderate solar activity the E and HP type ratios are significantly lower than 1 as well as for the $\mathrm{N}$ type under high solar activity. Ratios computed only with days with a probability (to be correctly classified) higher than $75 \%$ (not shown), allowing us to omit some potentially erroneous weather type data, show similar results as in Fig. 5. The potential misclassified days have therefore no significant impact on our results.

For low solar activity, the decrease in the occurrence of the W type is also visible with a 1-, 2-, and 3-year lag (Fig. 6), but the decreased frequency of the WSW type is only visible with a 1-year lag. The increase in the occurrence of these two types under high solar activity is visible with a 1- and 2-year lag but disappears with a 3 -year lag. It is even significant 

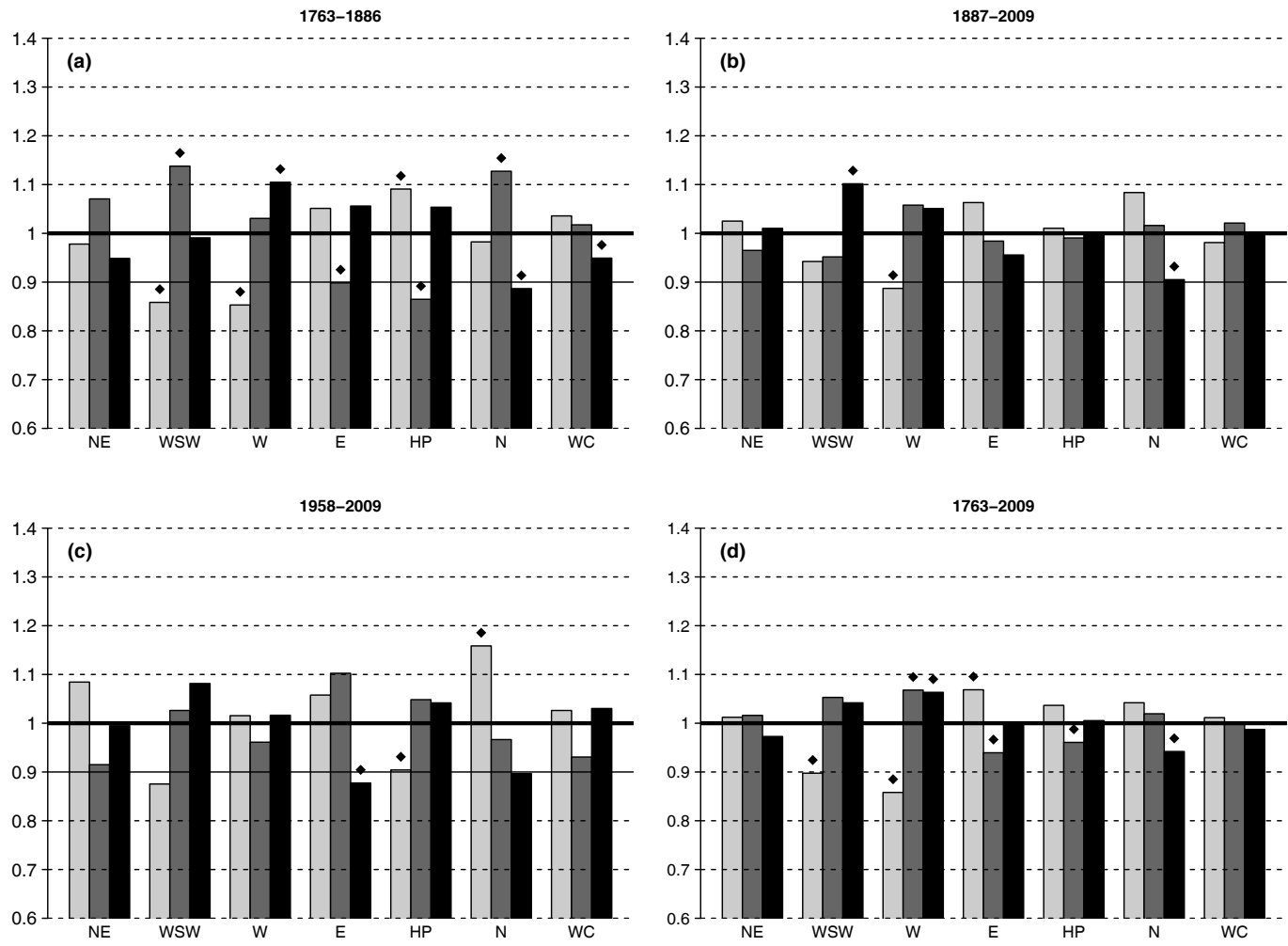

Figure 5. Ratios of the frequency for the low (light grey), moderate (grey), and high (black) solar activity classes relative to the long-term mean for different periods. Dots correspond to statistical significance of the ratios at the $95 \%$ level.

for the 2-year lag. The signal found in the $\mathrm{N}$ and $\mathrm{E}$ types is inverted with a 2- and 3-year lag (as compared to zero lag) with a reduction in the occurrence under low solar activity. The increase in the occurrence of the HP type under low solar activity is the strongest, with a 3 -year lag.

The main occurrence differences for the period 1763-2009 can be summarized as follows: the occurrence of $\mathrm{W}$ and WSW types decreases significantly under low solar activity. At the same time, we observe a significant higher occurrence frequency of the E type. The occurrence frequency of the W type increases significantly under moderate and high solar activity. The occurrence frequency of the E and $\mathrm{HP}(\mathrm{N})$ types is significantly lower under moderate (high) solar activity.

\subsection{Solar signal in weather types - within-type differences}

The inter-type analysis is complemented with a within-type analysis of their composites (Figs. 7 and 8). Difference composites were computed by subtracting the high from the low solar activity class composites. They were computed for the period 1958-2009 with ERA-40/Interim and are therefore not representative of the whole 1763-2009 period. Figure 7 displays the z500 (in gpdm) and blocking frequency (in \%) differences. Figure 8 displays the slp (in $\mathrm{hPa}$ ) and $\mathrm{t} 850$ (in ${ }^{\circ} \mathrm{C}$ ) differences. The weather types were originally computed with the slp over the Alpine region; thus the smallest slp differences are expected to be observed over this region. However, differences appear in the position and intensity of the high- and low-pressure centres. This can influence the general flow and thus the temperatures over Europe and the Alpine region.

With Figs. 7 and 8 we can identify the influence of the solar activity on each weather type and from this try to deduce a general influence on the tropospheric weather over Europe. The following descriptions always refer to the low solar activity class composite relative to the high-activity one. The mean JFM weather types slp and z500 composites are shown in Fig. 3.

1. NE: the low-pressure system south of Greenland extends more to the south and less from Iceland to Scandinavia. The anticyclone is weaker over western $\mathrm{Eu}$ rope but extends more towards Scandinavia. The lowpressure system over Italy is slightly deeper. The blocking frequency is higher from Greenland to Scandinavia but lower further south over the Atlantic. These changes in the pressure pattern lead to lower temperature over the whole European continent.

2. WSW: the low-pressure system located between Iceland and Scotland is less pronounced over northern Europe. The mean z500 is higher between the British Isles 

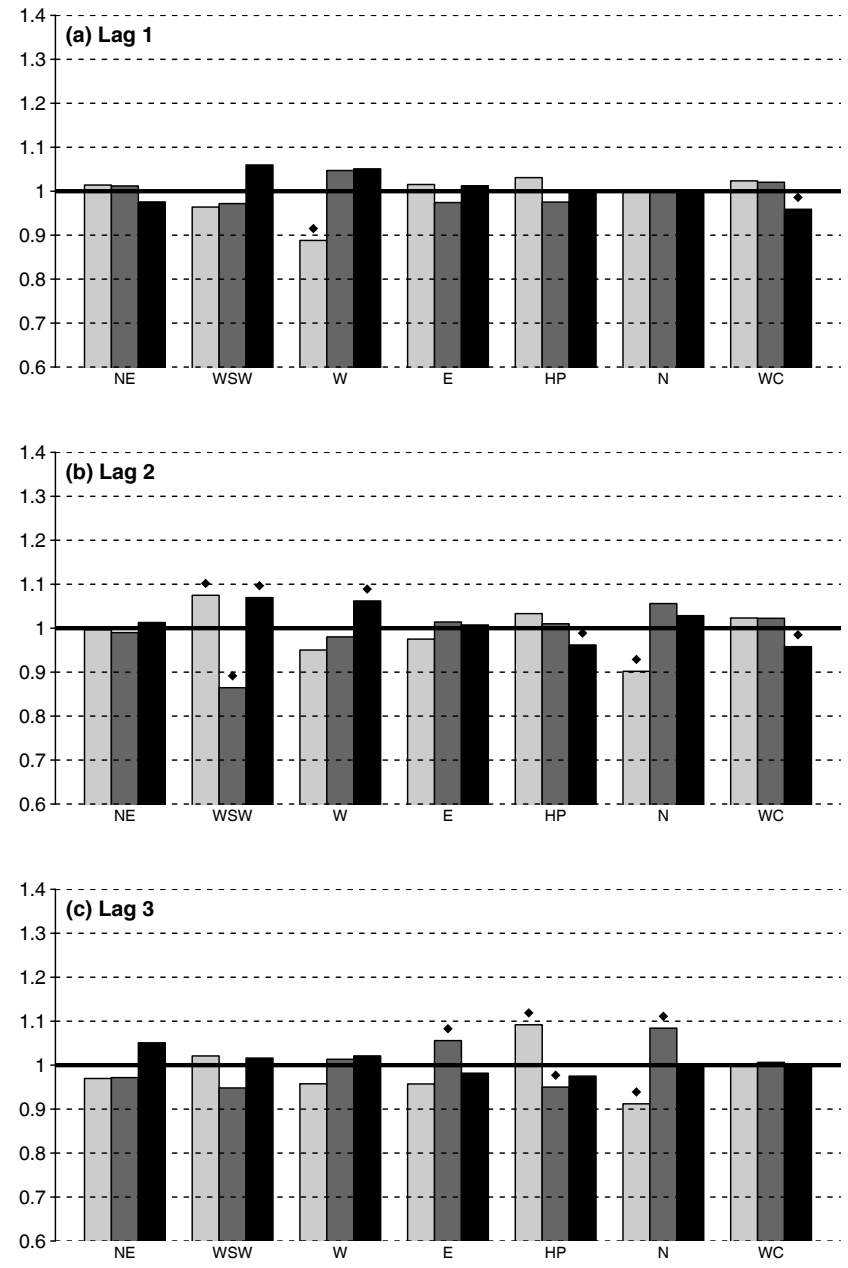

Figure 6. Ratios of the frequency for the low (light grey), moderate (grey), and high (black) solar activity classes for 1-year (a), 2-year (b), and 3-year (c) lags relative to the long-term mean. Dots correspond to statistical significance of the ratios at the $95 \%$ level.

and Scandinavia, and lower over eastern Europe and the Mediterranean. The same pattern is visible in the temperature differences. Small differences in the blockings with higher frequencies over Scandinavia are also visible.

3. W: the pressure over Iceland is reduced whereas the Azores anticyclone is more pronounced over the western Atlantic; the pressure gradient is tighter. The pressure is higher over Scandinavia and the anticyclone is more prevalent over southern Europe with a higher blocking frequency. Temperatures are therefore lower over most parts of Europe.

4. E: the pressure is higher between Greenland and Scandinavia, as is the blocking frequency. The anticyclone extends more over Europe and the pressure is lower over the Mediterranean Sea. The temperature is reduced over all Europe except Scandinavia.

5. HP: the pressure and z500 are higher over most of the North Atlantic and northern Europe, whereas they are lower over southern Europe and northern Africa. The blocking frequency is higher over all Europe. The temperature is reduced over Europe especially in the eastern part.

6. $\mathrm{N}$ : the pressure and $\mathrm{z} 500$ are higher over Scandinavia and lower over the western Mediterranean Sea and eastern Atlantic. The flow is more oriented northeasterly than northwesterly over central Europe with reduced temperature.

7. WC: the Azores anticyclone is more pronounced and the low-pressure system between the British Isles and Scandinavia is weaker but extends more towards the Mediterranean Sea. The temperatures are reduced over southwestern Europe and northern Africa, whereas they are warmer over northeastern Europe.

Similar patterns can be observed among groups of weather types. Types $1(\mathrm{NE}), 4(\mathrm{E})$, and $6(\mathrm{~N})$ all have an enhanced easterly flow over central Europe under low solar activity and thus lower temperatures. All three types also have more frequent Scandinavian blockings. Types 2 (WSW) and 3 (W) have a slightly reduced westerly flow over central Europe. On average (All in Figs. 7 and 8, as well as Fig. 4) we see a higher pressure between Iceland and Scandinavia, and lower pressure over the Mediterranean Sea under low solar activity. The blocking frequency is higher between Iceland and Scandinavia, too. This leads to a weaker pressure gradient and westerly flow over Europe. Following this reduction in the zonal flow, temperatures tend to be lower over Europe (except Scandinavia). Outside Europe we note an increase in temperature over the high latitudes in all cases especially around Greenland.

\section{Discussion}

The reduced zonal flow and colder temperatures over Europe under low solar activity (Fig. 4) are consistent with other studies (e.g. Brugnara et al., 2013; Ineson et al., 2011; Sfîca et al., 2015; Sirocko et al., 2012; Woollings et al., 2010). It was found in several studies that the signal in slp under low (high) solar activity resembles a negative (positive) NAO pattern (e.g. Ineson et al., 2011; Sfîca et al., 2015; Thiéblemont et al., 2015). As suggested in Thiéblemont et al. (2015) there is no direct correlation between solar activity and the NAO but a synchronization following the downward propagation of the solar signal from the stratosphere to the troposphere. However, although there is a clear reduction in the zonal flow under low solar activity compared to high activity in our results over Europe (Fig. 4), this signal does not 

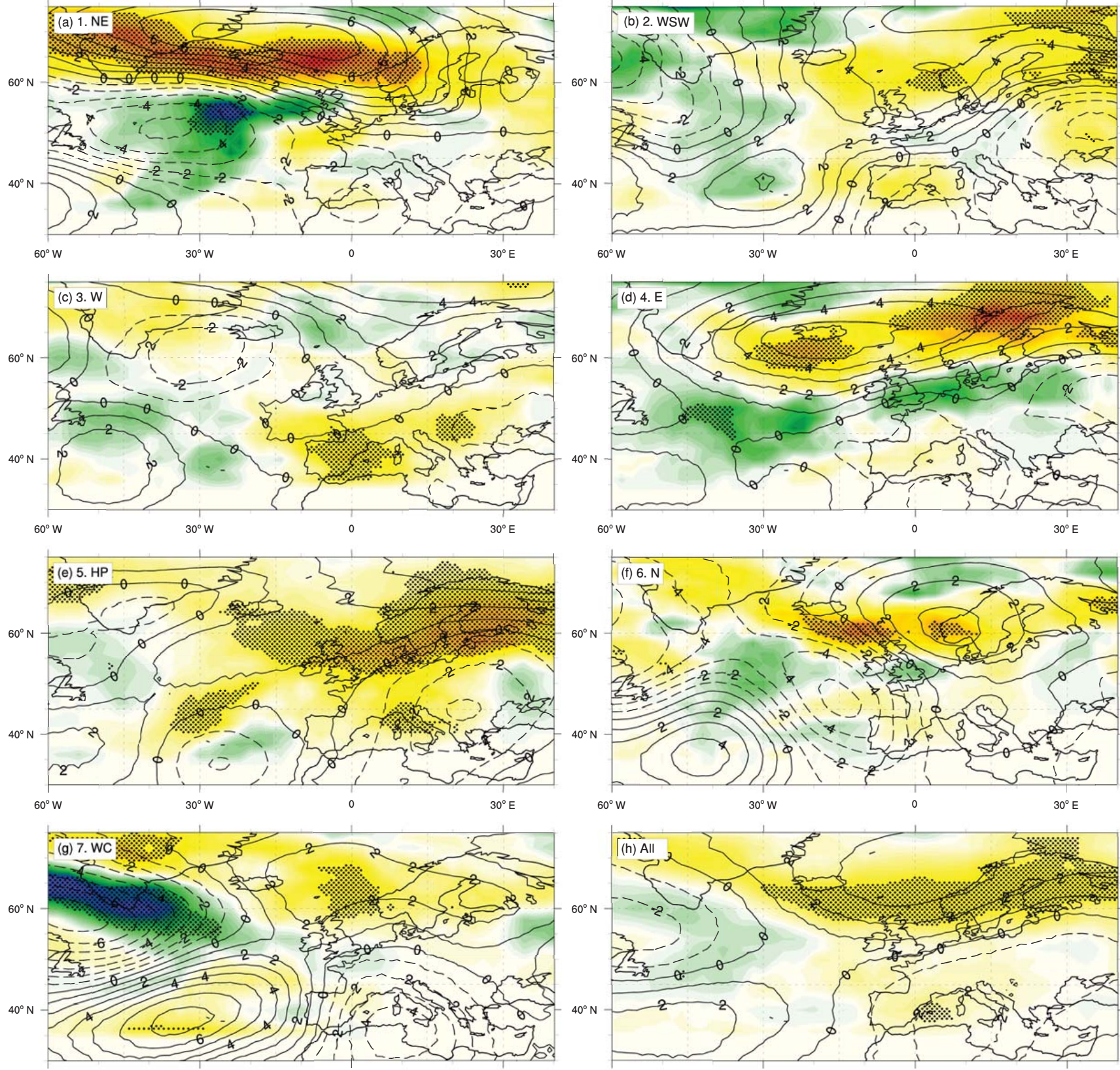

$60^{\circ} \mathrm{W} \quad 30^{\circ} \mathrm{W}$

$30^{\circ} \mathrm{E}$

$60^{\circ} \mathrm{W}$

$30^{\circ} \mathrm{W}$

$30^{\circ}$

$\begin{array}{lllllllllllllllll}-16 & -14 & -12 & -10 & -8 & -6 & -4 & -2 & 0 & 2 & 4 & 6 & 8 & 10 & 12 & 14 & 16\end{array}$

Figure 7. CAP7 (1 to 7) and mean (All) JFM blocking frequency (colour) in \% and $500 \mathrm{hPa}$ geopotential height (contour) in gpdm difference between low and high solar activity (low minus high) computed with ERA-40/Interim for the period 1958-2009. The 95\% significance level is indicated by stippled areas.

match any phase of the NAO. Thus, it seems that the 11year cycle does not directly modulate the NAO but projects more onto an west-east pattern between the Labrador Sea and western Russia. Other studies corroborate this pattern with a solar signal extending towards Eurasia (Brugnara et al., 2013; Woollings et al., 2010). For Brugnara et al. (2013) the Eurasian index is more linked to the 11-year cycle than the NAO. The differences in the blocking index confirm the reduced zonal flow under low solar activity with a higher blocking frequency over the Norwegian Sea and Scandinavia. Similarly, Barriopedro et al. (2008) found an increase in the blocking frequency over the eastern Atlantic under low 

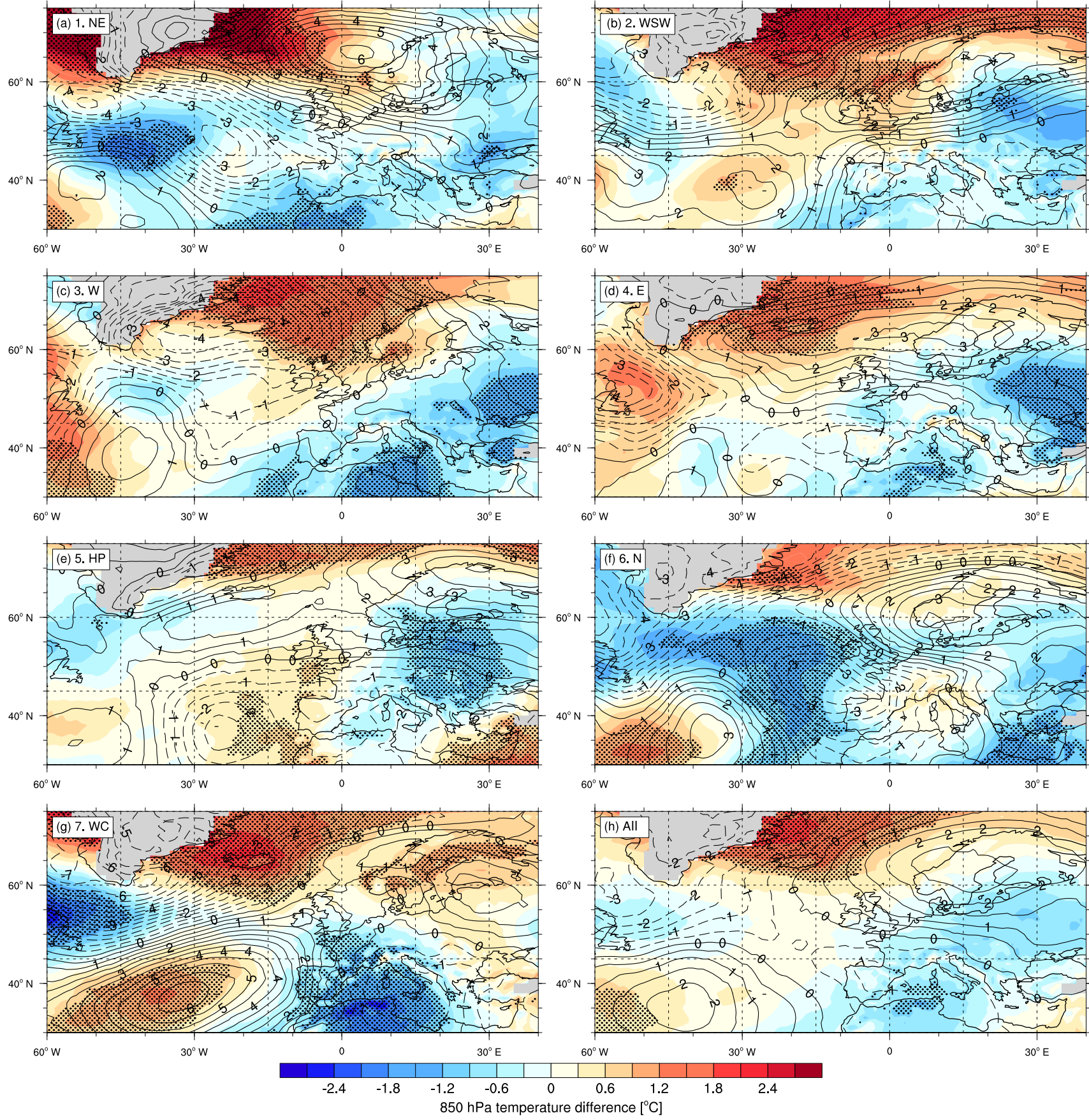

Figure 8. CAP7 (1 to 7) and mean (All) JFM sea level pressure (contour) in hPa and $850 \mathrm{hPa}$ temperature (colour) in ${ }^{\circ} \mathrm{C}$ difference between low and high solar activity (low minus high) computed with ERA-40/Interim for the period 1958-2009. The $95 \%$ significance level is indicated by stippled areas.

solar activity. They also found that Atlantic blockings are located further east under low solar activity which corresponds to our result with a higher blocking frequency towards the east of the Atlantic.

The differences in weather type occurrences during the period 1958-2009 (Fig. 5c) correspond with the results of Huth et al. (2008b). This is especially the case for the WSW type with a decrease in its occurrence under low solar activity. The $\mathrm{N}$ type shows also the same pattern as in Huth et al. (2008b) with an increase (decrease) in the occurrence under low (high) solar activity. The differences in these two types (WSW and N) are also confirmed in the long-term differences in our results (1763-2009, Fig. 5d). Under low (high) solar activity the frequency of occurrence of $\mathrm{W}$ and 
WSW types decreases (increases). This consecutively results in an increase in the frequency of $\mathrm{E}, \mathrm{HP}$, and $\mathrm{N}$ types under low solar activity. The reduction (increase) in the occurrence of W and WSW (E) types is the largest difference in the ratios between one solar activity class and the long-term mean that we observe and it still persists over both sub-periods (17631886 and 1887-2009). However, certain types (e.g. NE) do not have the same signal under both sub-periods. These types could be more sensitive to internal variability or to the influence of others forcings. This persistence of this signal over time in the WSW and W types supports the hypothesis that the 11-year solar cycle has an influence on the occurrence of European weather types.

The differences in the occurrence between low and high solar activity of some weather types (NE, WSW, E, and N) during the period 1958-2009 (Fig. 5c) can partly explain lower temperatures under low solar activity over Europe (Fig. 4). These changes in the occurrence of weather types are consistent with a weaker (stronger) zonal flow over Europe as has been suggested in several studies (e.g. Ineson et al., 2011; Sfî̀ca et al., 2015).

A lagged response of the NAO following a solar maximum was suggested in Gray et al. (2013) and Thiéblemont et al. (2015). Our results with a 1- and 2-year lag (Fig. 6) showing a higher occurrence of westerly types under high solar activity does not rule out the hypothesis of a delayed signal. However, we do not observe any signal with 3-year lag (Fig. 6c) under high solar activity. Under low solar activity the weather type occurrences are similar at zero lag and a 1-year lag (reduction in W and WSW types; slight increase in $\mathrm{E}$ and $\mathrm{HP}$ types). The signal found in the $\mathrm{N}$ type with zero lag is inverted with a 2- and 3-year lag (reduction in the occurrence under low solar activity). Our results do not support previous findings suggesting that the strongest solar signal over Europe is visible with a lag.

The mesoscale circulation variations can explain the changes in the frequency of occurrence of the $\mathrm{E}$ and $\mathrm{W}$ weather patterns over central Europe. A weaker zonal flow as seen in Fig. 4 leads to a reduction of the occurrences of westerly types and thus to an increase in the occurrence of easterly types (continental flow). These pattern changes are also consistent with a higher blocking index over Scandinavia under low solar activity. Blockings over high European latitudes are often responsible for the establishment of an easterly flow over central Europe. We also observe - from 1958 to 2009 not only a change in the weather type occurrences but also of the slp patterns of each weather type (Figs. 7 and 8). For the W and WSW types we observe a reduction in the slp between Greenland and Iceland under low solar activity. This pattern over the North Atlantic resembles a positive NAO phase, which is in contradiction with previous studies (e.g. Ineson et al., 2011; Thiéblemont et al., 2015). However, further east (toward Scandinavia) the pressure is higher under low solar activity which leads to reduced flow of maritime air masses to central Europe and lower temperatures. Again, it seems that the 11-year cycle does not directly modulate the NAO but shows more of an west-east pattern between the Labrador Sea and western Russia. As mentioned above, other studies corroborate this pattern with a solar signal extending toward Eurasia (Brugnara et al., 2013; Woollings et al., 2010).

As mentioned above, an increase in slp and blockings over Scandinavia as well as a decrease in slp over the Mediterranean Sea are synonymous with an enhanced continental flow over central Europe. We notice a double effect with an increase in the occurrence of NE, E, and $\mathrm{N}$ types (inter-type) under low solar activity but also a stronger mean easterly flow based on their composites for the period 1958-2009 (within-type). The same holds for the WSW type, which is less frequent, and the associated zonal flow to this pattern is also slightly weaker over central Europe. The stronger (weaker) continental (zonal) flow under low solar activity brings cold air from the Eurasian continent and diminishes the influence of the warm oceanic air over central Europe. Following these circulation changes we estimate that there is a higher (lower) probability to have cold winter during the weak (strong) phase of the 11-year solar cycle. Other studies (Lockwood et al., 2010; Sirocko et al., 2012) found similar results, with cold European winters being often linked to weak solar activity.

\section{Conclusions}

We have used a new weather type classification to analyse the impact of the 11-year solar cycle on European weather in late winter. The monthly sunspot number was used as a measure of solar activity and the daily weather types were retrieved from the CAP7 classification. We have analysed changes in the frequency of occurrence of the CAP7 weather types under three different solar activity levels (low, moderate, high) from 1763 to 2009 and analysed as well the within-type differences between low and high solar activity from 1958 to 2009 in reanalyses data.

The strongest solar signal visible in the occurrence of the CAP7 weather types is a reduction in the number of days with westerly and west-southwesterly flow under low solar activity, and consequently in the number of days with northerly or easterly flow, and high-pressure increases. Conversely, the occurrence of both westerly and west-southwesterly types increases under moderate and high solar activity. The analysis of within-type differences under low and high solar activity phases confirms not only that the frequency of occurrence of some weather types respond to change in the solar activity, but also that the mean patterns of these types are slightly different. The zonal flow characteristic of westerly types is reduced under low solar activity as the continental flow for easterly and northerly types is enhanced. This is also confirmed by the higher blocking frequency over Scandinavia under low solar activity. The 247- 
year-long analysis of the 11-year solar cycle impact on late winter European weather patterns suggests a reduction in the occurrence of westerly flow types linked to a reduced mean zonal flow under low solar activity. Based on this observational evidence, we estimate the probability to have cold conditions in winter over Europe to be higher under low solar activity than under high activity.

Data availability. Weather types and data used in this paper are available from the corresponding author upon request.

Competing interests. The authors declare that they have no conflict of interest.

Acknowledgements. This work was funded by the Swiss National Science Foundation through the Sinergia FUPSOL II (number 147659) and project EXTRA-LARGE (number 143219). We thank ECMWF for providing ERA-40 and ERA-Interim data. We also thank the World Data Center (WDX-SILSO, Royal Observatory of Belgium, Brussels) for the production, preservation, and dissemination of the international Sunspot Number.

Edited by: Jürg Luterbacher

Reviewed by: two anonymous referees

\section{References}

Andersson, M. E., Verronen, P. T., Rodger, C. J., Clilverd, M. A., and Seppälä, A.: Missing driver in the Sun-Earth connection from energetic electron precipitation impacts mesospheric ozone, Nat. Commun., 5, 5197, https://doi.org/10.1038/ncomms6197, 2014.

Arfeuille, F., Weisenstein, D., MacK, H., Rozanov, E., Peter, T., and Brönnimann, S.: Volcanic forcing for climate modeling: A new microphysics-based data set covering years 1600present, Clim. Past, 10, 359-375, https://doi.org/10.5194/cp-10359-2014, 2014.

Baldwin, M. P. and Dunkerton, T. J.: The solar cycle and stratosphere-troposphere dynamical coupling, J. Atmos. Sol.-Terr. Phy., 67, 71-82, https://doi.org/10.1016/j.jastp.2004.07.018, 2005.

Barriopedro, D., García-Herrera, R., and Huth, R.: Solar modulation of Northern Hemisphere winter blocking, J. Geophys. Res.-Atmos., 113, 1-11, https://doi.org/10.1029/2008JD009789, 2008.

Brugnara, Y., Brönnimann, S., Luterbacher, J., and Rozanov, E.: Influence of the sunspot cycle on the Northern Hemisphere wintertime circulation from long upper-air data sets, Atmos. Chem. Phys., 13, 6275-6288, https://doi.org/10.5194/acp-136275-2013, 2013.

Dee, D. P., Uppala, S. M., Simmons, A. J., Berrisford, P., Poli, P., Kobayashi, S., Andrae, U., Balmaseda, M. A., Balsamo, G., Bauer, P., Bechtold, P., Beljaars, A. C. M., van de Berg, L., Bidlot, J., Bormann, N., Delsol, C., Dragani, R., Fuentes, M., Geer,
A. J., Haimberger, L., Healy, S. B., Hersbach, H., Hólm, E. V., Isaksen, L., Kållberg, P., Köhler, M., Matricardi, M., Mcnally, A. P., Monge-Sanz, B. M., Morcrette, J. J., Park, B. K., Peubey, C., de Rosnay, P., Tavolato, C., Thépaut, J. N., and Vitart, F.: The ERA-Interim reanalysis: Configuration and performance of the data assimilation system, Q. J. R. Meteor. Soc., 137, 553-597, https://doi.org/10.1002/qj.828, 2011.

Gimeno, L., de la Torre, L., Nieto, R., García, R., Hernández, E., and Ribera, P.: Changes in the relationship NAONorthern hemisphere temperature due to solar activity, Earth Planet. Sc. Lett., 206, 15-20, https://doi.org/10.1016/S0012821X(02)01090-7, 2003.

Gray, L. J., Beer, J., Geller, M., Haigh, J. D., Lockwood, M., Matthes, K., Cubasch, U., Fleitmann, D., Harrison, G., Hood, L., Luterbacher, J., Meehl, G. A., Shindell, D., van Geel, B., and White, W.: Solar influence on climate, Rev. Geophys., 48, RG4001, https://doi.org/10.1029/2009RG000282, 2010.

Gray, L. J., Scaife, A. A., Mitchell, D. M., Osprey, S., Ineson, S., Hardiman, S., Butchart, N., Knight, J., Sutton, R., and Kodera, K.: A lagged response to the 11 year solar cycle in observed winter Atlantic/European weather patterns, J. Geophys. Res.-Atmos., 118, 13405-13420, https://doi.org/10.1002/2013JD020062, 2013.

Haigh, D. J.: The effects of solar variability on the Earth's climate, Philos. T. Roy. Soc. Lond. A, 361, 95-111, https://doi.org/10.1098/rtsa.2002.1111, 2003.

Hood, L. L., Misios, S., Mitchell, D. M., Rozanov, E., Gray, L. J., Tourpali, K., Matthes, K., Schmidt, H., Chiodo, G., Thiéblemont, R., Shindell, D., and Krivolutsky, A.: Solar signals in CMIP5 simulations: The ozone response, Q. J. R. Meteor. Soc., 141, 2670-2689, https://doi.org/10.1002/qj.2553, 2015.

Huth, R., Bochníček, J., and Hejda, P.: The 11 year solar cycle affects the intensity and annularity of the Arctic Oscillation, J. Atmos. Sol.-Terr. Phys., 69, 1095-1109, https://doi.org/10.1016/j.jastp.2007.03.006, 2007.

Huth, R., Beck, C., Philipp, A., Demuzere, M., Ustrnul, Z., Cahynová, M., Kyselý, J., and Tveito, O. E.: Classifications of atmospheric circulation patterns: Recent advances and applications, Ann. NY Acad. Sci., 1146, 105-152, https://doi.org/10.1196/annals.1446.019, 2008a.

Huth, R., Kyselý, J., Bochnícek, J., and Hejda, P.: Solar activity affects the occurrence of synoptic types over Europe, Ann. Geophys., 26, 1999-2004, https://doi.org/10.5194/angeo-26-19992008, 2008b.

Ineson, S., Scaife, A. A., Knight, J. R., Manners, J. C., Dunstone, N. J., Gray, L. J., and Haigh, J. D.: Solar forcing of winter climate variability in the Northern Hemisphere, Nat. Geosci., 4, 753-757, https://doi.org/10.1038/ngeo1282, 2011.

Lockwood, M.: Solar Influence on Global and Regional Climates, Surv. Geophys., 33, 503-534, https://doi.org/10.1007/s10712012-9181-3, 2012.

Lockwood, M., Harrison, R. G., Woollings, T., and Solanki, S. K.: Are cold winters in Europe associated with low solar activity?, Environ. Res. Lett., 5, 24001, https://doi.org/10.1088/17489326/5/2/024001, 2010.

Martin-Puertas, C., Matthes, K., Brauer, A., Muscheler, R., Hansen, F., Petrick, C., Aldahan, A., Possnert, G., and van Geel, B.: Regional atmospheric circulation shifts in- 
duced by a grand solar minimum, Nat. Geosci., 5, 397-401, https://doi.org/10.1038/ngeo1460, 2012.

Matthes, K., Kodera, K., Haigh, J. D., Shindell, D. T., Shibata, K., Langematz, U., Rozanov, E., and Kuroda, Y.: GRIPS Solar Experiments Intercomparison Project: Initial results, Pap. Meteorol. Geophys., 54, 71-90, https://doi.org/10.2467/mripapers.54.71, 2003

Matthes, K., Langematz, U., Gray, L. J., Kodera, K., and Labitzke, $\mathrm{K}$.: Improved 11 year solar signal in the freie universitat Berlin climate middle atmosphere model (FUB-CMAM), J. Geophys. Res., 109, 1-15, https://doi.org/10.1029/2003JD004012, 2004.

Misios, S., Mitchell, D. M., Gray, L. J., Tourpali, K., Matthes, K., Hood, L., Schmidt, H., Chiodo, G., Thiéblemont, R., Rozanov, E., and Krivolutsky, A.: Solar signals in CMIP-5 simulations: Effects of atmosphere-ocean coupling, Q. J. R. Meteor. Soc., 142, 928-941, https://doi.org/10.1002/qj.2695, 2016.

Mitchell, D. M., Misios, S., Gray, L. J., Tourpali, K., Matthes, K., Hood, L., Schmidt, H., Chiodo, G., Thieblemont, R., Rozanov, E., Shindell, D., and Krivolutsky, A.: Solar signals in CMIP-5 simulatioms: she stratospheric pathway, Q. J. R. Meteor. Soc., 141, 2390-2403, https://doi.org/10.1002/qj.2530, 2015.

Moffa-Sánchez, P., Born, A., Hall, I. R., Thornalley, D. J. R., and Barker, S.: Solar forcing of North Atlantic surface temperature and salinity over the past millennium, Nat. Geosci., 7, 275-278, https://doi.org/10.1038/NGEO2094, 2014.

Päivärinta, S. M., Seppälä, A., Andersson, M. E., Verronen, P. T., Thölix, L., and Kyrölä, E.: Observed effects of solar proton events and sudden stratospheric warmings on odd nitrogen and ozone in the polar middle atmosphere, J. Geophys. Res.-Atmos., 118, 6837-6848, https://doi.org/10.1002/jgrd.50486, 2013.

Philipp, A., Bartholy, J., Beck, C., Erpicum, M., Esteban, P., Fettweis, X., Huth, R., James, P., Jourdain, S., Kreienkamp, F., Krennert, T., Lykoudis, S., Michalides, S. C., PiankoKluczynska, K., Post, P., Álvarez, D. R., Schiemann, R., Spekat, A., and Tymvios, F. S.: Cost733cat - A database of weather and circulation type classifications, Phys. Chem. Earth, 35, 360-373, https://doi.org/10.1016/j.pce.2009.12.010, 2010.

Philipp, A., Beck, C., Huth, R., and Jacobeit, J.: Development and comparison of circulation type classifications using the COST 733 dataset and software, Int. J. Climatol., 36, 2673-2691, https://doi.org/10.1002/joc.3920, 2014.

Robock, A.: Volcanic eruptions and climate, Rev. Geophys., 38, 191-219, https://doi.org/10.1029/1998RG000054, 2000.

Rozanov, E., Calisto, M., Egorova, T., Peter, T., and Schmutz, W.: Influence of the Precipitating Energetic Particles on Atmospheric Chemistry and Climate, Surv. Geophys., 33, 483-501, https://doi.org/10.1007/s10712-012-9192-0, 2012.

Scherrer, S. C., Croci-Maspoli, M., Schwierz, C., and Appenzeller, C.: Two-dimensional indices of atmospheric blocking and their statistical relationship with winter climate patterns in the Euro-Atlantic region, Int. J. Climatol., 26, 233-249, https://doi.org/10.1002/joc.1250, 2006.

Schwander, M., Brönnimann, S., Delaygue, G., Rohrer, M., Auchmann, R., and Brugnara, Y.: Reconstruction of Central European daily weather types back to 1763 , Int. J. Climatol., 37, 30-44, https://doi.org/10.1002/joc.4974, 2017.

Seppälä, A., Matthes, K., Randall, C. E., and Mironova, I. A.: What is the solar influence on climate? Overview of activ- ities during CAWSES-II, Prog. Earth Planet. Sci., 1, 1-12, https://doi.org/10.1186/s40645-014-0024-3, 2014.

Sfîca, L., Voiculescu, M., and Huth, R.: The influence of solar activity on action centres of atmospheric circulation in North Atlantic, Ann. Geophys., 33, 207-215, https://doi.org/10.5194/angeo-33207-2015, 2015.

Sirocko, F., Brunck, H., and Pfahl, S.: Solar influence on winter severity in central Europe, Geophys. Res. Lett., 39, 2-6, https://doi.org/10.1029/2012GL052412, 2012.

Sitnov, S. A.: Influence of the 11 year solar cycle on the effects of the equatorial quasi-biennial oscillation, manifesting in the extratropical northern atmosphere, Clim. Dynam., 32, 1-17, https://doi.org/10.1007/s00382-007-0362-6, 2009.

Solomon, S., Crutzen, P. J., and Roble, R. G.: Photochemical coupling between the thermosphere and the lower atmosphere: 1. Odd nitrogen from 50 to $120 \mathrm{~km}$, J. Geophys. Res., 87, 7206, https://doi.org/10.1029/JC087iC09p07206, 1982.

Soukharev, B. E. and Hood, L. L.: Solar cycle variation of stratospheric ozone: Multiple regression analysis of long-term satellite data sets and comparisons with models, J. Geophys. Res.-Atmos., 111, 1-18, https://doi.org/10.1029/2006JD007107, 2006.

Stevens, M. J. and North, G. R.: Detection of the climate response to the solar cycle, J. Atmos. Sci., 53, 2594-2608, https://doi.org/10.1175/1520 0469(1996)053<2594:DOTCRT>2.0.CO;2, 1996.

Thiéblemont, R., Matthes, K., Omrani, N.-E., Kodera, K., and Hansen, F.: Solar forcing synchronizes decadal North Atlantic climate variability, Nat. Commun., 6, 8268, https://doi.org/10.1038/ncomms9268, 2015.

Tibaldi, S. and Molteni, F.: On the operational predictability of blocking, Tellus A, 42, 343-365, https://doi.org/10.1034/j.16000870.1990.t01-2-00003.x, 1990.

Uppala, S. M., Kallberg, P. W., Simmons, A. J., Andrae, U., Bechtold, V. D., Fiorino, M., Gibson, J. K., Haseler, J., Hernandez, A., Kelly, G. A., Li, X., Onogi, K., Saarinen, S., Sokka, N., Allan, R. P., Andersson, E., Arpe, K., Balmaseda, M. A., Beljaars, A. C. M., Van De Berg, L., Bidlot, J., Bormann, N., Caires, S., Chevallier, F., Dethof, A., Dragosavac, M., Fisher, M., Fuentes, M., Hagemann, S., Holm, E., Hoskins, B. J., Isaksen, L., Janssen, P. A. E. M., Jenne, R., McNally, A. P., Mahfouf, J. F., Morcrette, J. J., Rayner, N. A., Saunders, R. W., Simon, P., Sterl, A., Trenberth, K. E., Untch, A., Vasiljevic, D., Viterbo, P., and Woollen, J.: The ERA-40 re-analysis, Q. J. R. Meteor. Soc., 131, 29613012, https://doi.org/10.1256/qj.04.176, 2005.

Van Loon, H. and Meehl, G. A.: Interactions between externally forced climate signals from sunspot peaks and the internally generated Pacific Decadal and North Atlantic Oscillations, Geophys. Res. Lett., 41, 161-166, https://doi.org/10.1002/2013GL058670, 2014.

Van Oldenborgh, G. J., Laat, A. T. J. De, Luterbacher, J., Ingram, W. J., and Osborn, T. J.: Claim of solar influence is on thin ice: are 11 year cycle solar minima associated with severe winters in Europe?, Environ. Res. Lett., 8, 24014, https://doi.org/10.1088/1748-9326/8/2/024014, 2013.

Weusthoff, T.: Weather Type Classification at MeteoSwiss - Introduction of new automatic classification schemes, Arbeitsberichte der MeteoSchweiz, 235, 46, 2011. 
White, W. B., Lean, J., Cayan, D. R., and Dettinger, M. D.: Response of global upper ocean temperature to changing solar irradiance, J. Geophys. Res., 102, 3255-3266, https://doi.org/10.1029/96JC03549, 1997.
Woollings, T., Lockwood, M., Masato, G., Bell, C., and Gray, L.: Enhanced signature of solar variability in Eurasian winter climate, Geophys. Res. Lett., 37, 1-6, https://doi.org/10.1029/2010GL044601, 2010. 